\title{
How Can B2B E-Marketplaces (EM) Enhance the Quality of Supply Chain?
}

\author{
Bahar Movahedi, Kayvan M. Lavassani and Vinod Kumar \\ Carleton University, Eric Sprott School of Business, 1125 Colonel By Drive, 710 Dunton \\ Tower, Ottawa K1S 5B6, Ontario, Canada \\ \{mbahar,kmlavassa,vinod_kumar\}@connect.carleton.ca
}

\begin{abstract}
Supply Chain Management (SCM) is a source of competitive advantage in organizations especially for those organizations that supply chain (SC) is the core of their business or is tightly coupled with their core business. Traditionally organizations use re-engineering practices and organizational enhancement programs in order to increase their competitive advantage through optimizing their supply chain management. With advancement of technologies organizations begun to fabricate processes and employ more advanced communication technologies and technological tools -such as E-Marketplaces (EM) and RFID tags - with the goal of increasing the quality of their SC. The objective of this paper is to shed light on the concept of quality in SC, and application of B2B EMs for enhancing the quality of their supply chain. Moreover the adoption process and critical factors affecting the success of EM adoption in $\mathrm{SC}$ is explored in this study.
\end{abstract}

Keywords: E-Business, E-Commerce, Electronic marketplace, Interorganizational enterprise systems, Supply chain management

\section{SUPPLY CHAIN QUALITY}

Supply Chain (SC) is a process that deals with planning, sourcing, making, and delivery activities [1]. In this part we first describe the scope of SC quality and then explore the multi-dimensional concept of quality of SC.

\subsection{Scope of Supply Chain Quality}

For understanding the concept of quality in the context of SC it is necessary to first explore the scope of SC quality. Robinson and Malhotra [1], in their article, presented the evolutionary timeline, programs, and the focus of SC quality management from 1920 to the present time, in which they explain that until 1980 the focus of management was on the internal SC of the organizations. Since then, the focus of Supply Chain Management (SCM) has expanded beyond organizational boundaries.

Please use the following format when citing this chapter:

Monahedi, B., Lavassani, K. M., Kunar, V., 2007, in IFIP International Federation for Information Processing, Volume 255, Research and Practical Issues of Enterprise Information Systems II Volume 2, eds. L. Xu, Tjoa A., Chaudhry S. (Boston: Springer), pp. 857-867. 
While internal SC is mostly concerned with issues such as internally focused process integration and management, strategy, quality leadership, and quality practices, external SC is mainly concerned with externally focused inter-organizational integration and strategy, communication and partnership [1]. It is important to note that internal and external SCs are tightly coupled elements of a single process. Similarly, Chen and Paulraj [2] explain that the span of SCM goes beyond the organizational boundaries and is linked to suppliers and customers. From this perspective while internal $\mathrm{SC}$ is concerned with purchasing, production and distribution, external SC deals with suppliers and customers. A more detailed taxonomy of SC is presented by the Supply Chain Council [3] where the first tier and second tier suppliers and consumers are also identified. Robinson and Malhotra's [1] study recognized the development of the focus of SC quality from a merely internal organizational issue to an intra- and inter-organizational context.

Over the period of the 1960 s to the 1980 s the literature on quality management was mostly concerned with the quality of products [4]. One example is the seminal work of David Garvin [5], which stated that the quality is concerned with eight characteristics of product and the service associated with it (Table 1). This was the dominant view of the quality until the early $1990 \mathrm{~s}$, when the quality of services was differentiated from the quality of products. The first attempt on measuring the quality of service was done by Berry and Parasuraman [6]. In their seminal work on service quality, these authors identified five dimensions of the quality of services (Table 1). Madu and Madu [7-8] made significant contribution in identifying the dimensions of the quality of virtual service and operations, or what they call "e-quality". In their articles Madu and Madu [7-8] identified three types of quality: quality of products, quality of service, and quality of virtual operation. Madu and Madu [6] acknowledged the contribution of popular quality models presented by Garvin [9] on the quality of products and the contributions of Berry and Parasuraman [6] on the quality of services. However they point out that these models and their extensions developed by some scholars including Chase and Stewart [10] "have not dealt with the emerging area of e-commerce and the importance of developing dimensions to measure the quality of virtual operations" [6]. In response to this gap, Madu and Madu [6] in their article proposed 15 dimensions of the quality of $\mathrm{B} 2 \mathrm{~B}$ and $\mathrm{B} 2 \mathrm{C}$ virtual operations. Table 1 presents the dimensions of quality of products, services, and virtual operations from the works of Garvin [9], Berry and Parasuraman [6], and Madu and Madu [7].

The work of Madu and Madu [7] on dimensions of quality of virtual operations is not only limited to B2B type of e-commerce, but it also includes the B2C (Businessto-Customer) and B2G (Business-to-Government) types of e-commence. Quality of $\mathrm{SC}$ has similarities and differences with quality of products and services. While the quality of product and services are defined towards the customer, the quality of SC is defined towards the first tier and second tier forward and backward linkages and the intra-organizational activities. The quality of $S C$ is concerned with issues beyond the provision of products and services, issues such as collaboration, coordination, risk management, cultural change, etc. In the next section, the dimensions of quality of SC are explored explicitly. 
Table 1. Product Quality, Service Quality, and Virtual Operations Quality

\begin{tabular}{|l|l|ll|}
\hline \multicolumn{1}{|c|}{$\begin{array}{c}\text { Products } \\
\text { [5] }\end{array}$} & \multicolumn{1}{c|}{$\begin{array}{c}\text { Services } \\
\text { [6] }\end{array}$} & \multicolumn{2}{c|}{ Virtual Operations } \\
\hline -Performance & -Tangibles & -Trust & -Reputation \\
-Features & -Reliability & -Empathy & -Performance \\
-Reliability & -Responsiveness & -Features & -Serviceability \\
-Durability & -Assurance & -Structure & -Responsiveness \\
-Serviceability & -Empathy & -Assurance & -Storage capability \\
-Conformance & & -Aesthetics & -Web store policies \\
-Perceived & & -Reliability & \\
quality & & -Security and systems integrity \\
-Aesthetics & & -Product/Service differentiation and customization \\
\hline
\end{tabular}

\subsection{Dimensions of Supply Chain Quality}

There is a great deal of discussion in the literature about the dimensions and meaning of quality, however there is relatively less attention towards exploring the concept of the quality in SC. One way to look at the quality of SC is to assess the SC capacity in regards with the maximum level of supply, production, and delivery that $\mathrm{SC}$ can handle [10]. Another way of assessing the quality of SC is by measuring the utilization of SC, which is the ratio of capacity used to available capacity [11]. Another measure of the quality of SC is the efficiency of SC. Efficiency of SC is usually measured by the level of inventory and utilization of SC [12]. Quality can also be looked at from the performance perspective, where performance is defined as the ratio of actual output to the standard output $[11,13,14]$. Some performance indicators include: response time, throughput, compatibility, reliability [15], and cash-to-cash cycle time $^{1}[16]$.

A more recent view of the quality of SC focuses on the ability of SC in handling the risks. We identified flexibility, agility, resilience, and adaptability as the four dimensions of the quality of SC which reflect the ability of SC to handle the risks at different levels. While flexibility is mainly concerned with small disruptions, the resilience aspect of SC quality deals with large disruptions. Also, while agility refers to the ability of SC to recover from a short-term change, adaptability deals with the ability of SC to adapt to a long-term change. After identifying the scope of SC quality, we explored the dimensions of SC quality. Table 2 presents the multidimensional aspects of SC quality. The quality of SC can be viewed from the perspective of capacity, utilization level, performance level, efficiency, flexibility, agility, resilience and adaptability.

\footnotetext{
' Cash-to-cash in a financial index which can be used in SC performance measurement as a proxy to measure the time products spend in the SC. The lower this number is, the higher the performance of SC will be.
} 
Table 2. Indicators of Supply Chain Quality

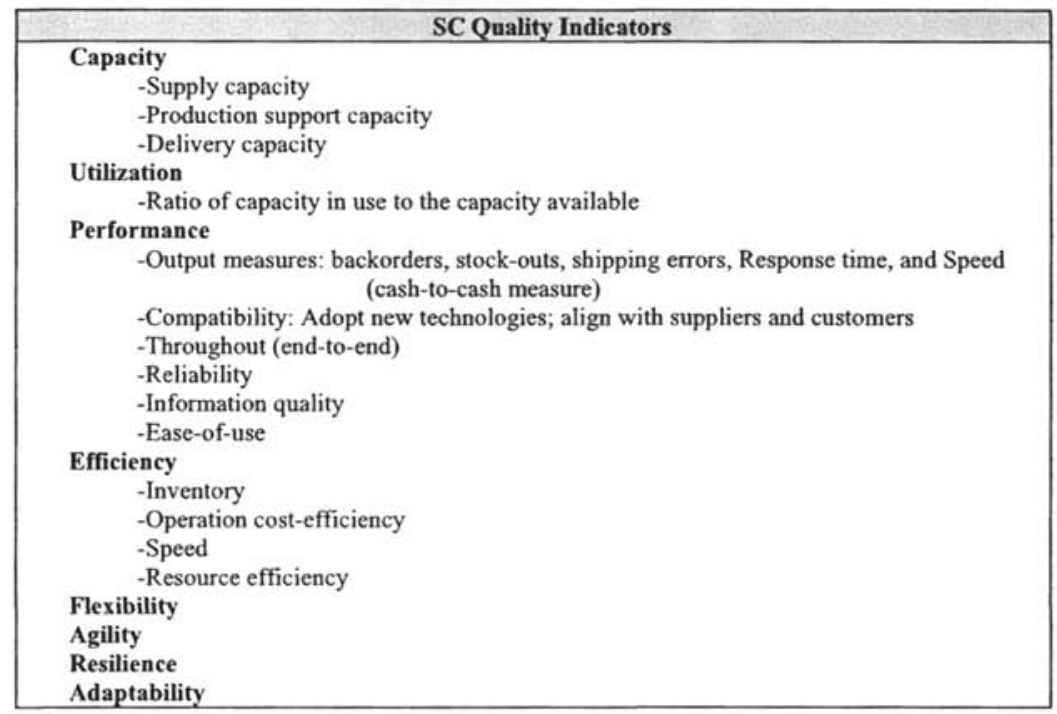

Table 3. SC Quality Enhancement Methods

\begin{tabular}{|c|c|c|}
\hline & SC Quality Enhancement & Author \\
\hline 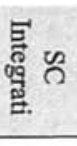 & $\begin{array}{l}\text { Inter-organizational integration of SC } \\
\text { Communication, collaboration and integration with } \\
\text { suppliers } \\
\text { Process integration }\end{array}$ & $\begin{array}{l}{[17]} \\
{[1],[24]} \\
{[1]}\end{array}$ \\
\hline 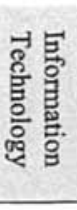 & $\begin{array}{l}\text { IT infrastructure } \\
\text { Database systems } \\
\text { IT-enabled logistics and production } \\
\text { IT-enabled marketing and after-sale services } \\
\text { Application of IT } \\
\text { IT-driven SC integration }\end{array}$ & $\begin{array}{l}{[18]} \\
{[18]} \\
{[18]} \\
{[18]} \\
{[19],[21],[20]} \\
{[18]}\end{array}$ \\
\hline 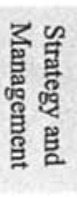 & $\begin{array}{l}\text { Selecting the Best Practices } \\
\text { Supply Chain Risk management (Flexibility, Agility, } \\
\text { Resilience, Adaptability) } \\
\text { Managing the cultural change } \\
\text { Committed and innovative management and } \\
\text { leadership }\end{array}$ & $\begin{array}{l}{[1]} \\
{[24],[12],[47],[48]} \\
{[12],[24]} \\
{[1]}\end{array}$ \\
\hline
\end{tabular}




\section{SUPPLY CHAIN QUALITY ENHANCEMENT}

Organizations use different methods for enhancing different dimensions of the quality of SC. Birachi [17] in his study explained that there is a positive relationship between the level of inter-organizational integration of SC and the level of quality of SC. As the market integration moves from spot market to specified contracts, strategic alliances, formal cooperation, and vertical integration different dimensions of the quality of SC increases.

In a study on the technology related factors affecting the quality of SC, Kuei and Madu [18] identified five factors that can enhance the quality of SC through the application of information technology (IT). These five factors are: IT infrastructure, database systems, IT-enabled logistics and production, IT-enabled marketing and after-sale services, and IT-driven SC integration. Based on a comprehensive literature review of major journals in the area of operational management, Robinson and Malhotra [1] identified five thematic linkages between quality and SCM research. These linkages are: communication and partnership activities, process integration and management, management and leadership, strategy, and following best practices. The implication of this study is that in order to increase the quality of SC, organizations should focus on these five constructs of SCM. Some researchers have focused explicitly on exploring the ways to enhance risk management aspects of $\mathrm{SC}$ quality. Christopher, et al. [24] explains that SC re-engineering is required to enhance the resilience of SC. This re-engineering includes activities such as "creating a $\mathrm{SC}$ risk management culture" in firms, increasing "SC collaboration and integration", and "enhancing the agility" of SC. According to Sheffi [12] SC resilience can be achieved through redundancy, flexibility, and cultural change. Table 3 presents a summery of ways proposed in the literature for enhancing the quality of SC. Based on our literature review we conclude that the quality of SC can be enhanced through three ways: integration of intra and inter organizational SCs, use of IT, and employing a number of strategic and managerial practices. These three enhancement solutions are highly interrelated. Application of IT and internet-based solutions is not only is an enabler for integration of SC [1-18] but also enhances the achievement of strategic and managerial goals [22-23]. Our proposed SC quality enhancement model presents the relationship between independent variables (IT application, SC integration, and Strategy \& Management) and SC quality (dependent variable). It also presents the interrelations among independent variables (Figure 1).

Electronic Data Interchange (EDI) systems, Enterprise Resource Planning (ERP) systems, and web-based solutions -including B2B EMs-are among the IT tools that organizations can use to integrate their $\mathrm{SC}$ and consequently increase the quality of their SC. In the past few years the web-based solutions for integrating the SC of organizations has attracted great attention both in industry and in academia. In the next section we will introduce $\mathrm{B} 2 \mathrm{~B}$ electronic marketplaces as one of the means of integration -and consequently- enhancement of quality of SC. 


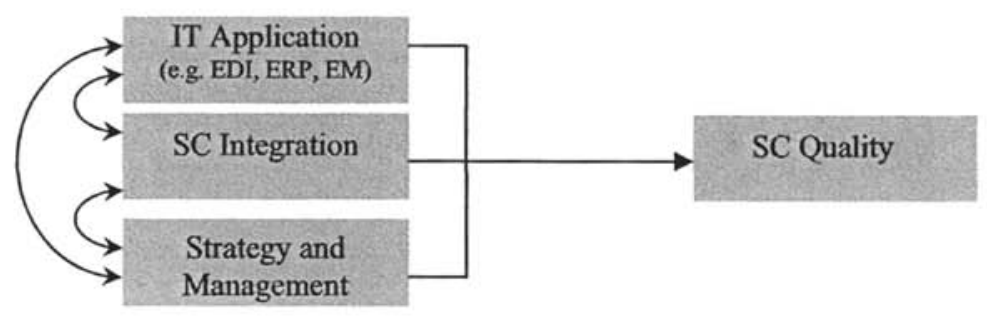

Figure 1. SC Quality Enhancement Model

\section{E-MARKETPLACES}

We introduced EMs as one of the IT solutions for enhancing the quality of SCs. Selection of the right type of EM in SC integration is one of the critical steps in transforming the traditional SC to EM enabled SC. This requires a clear understanding about what EM is and what are the different types of EMs. Therefore in this part of the paper we explore concept of EM, and propose a typology of EMs.

\subsection{E-Marketplaces}

EMs are new business models which are developing and changing rapidly [25-26]. Traditionally markets have three roles: facilitating the transaction, matching buyers and sellers, and provision of institutional infrastructure [27]. For the purpose of this study, we propose the following definition for the EMs: $e$-Marketplaces are effective and efficient collaborative Internet-based institutional infrastructures for interorganizational negotiation and transaction.

EMs can be differentiated from different perspectives. In this study we focused on B2B types [28] of EMs. Based on our literature review B2B EMs can be classified into different types based on six criteria: Vertical vs. Horizontal [29-31], Pricing Mechanism [31-33], B2B EMs Functionality [34-35], Ownership [35, 36], Biased vs. Third Party [26-38], and Closed vs. Open.

\section{ADOPTION OF B2B EMS IN SUPPLY CHAIN}

For adopting B2B EMs in SC, one of the most important issues facing the managers is the degree of readiness of the adopting organizations to undergo the change process. This readiness includes two aspects: the readiness of the organizations for SC collaboration, and the readiness of organizations to adopt the EM business model. In this part we also explore EM adoption success factors. 


\subsection{Supply Chain Collaboration Readiness}

In an empirical study Chang and Shaw [39] developed some indexes for measuring the degree of readiness of organizations to adopt IT enabled SC. In this study the authors identify three sets of factors affecting the readiness of SC collaboration. The factors include corporate IT readiness, $\mathrm{SC}$ readiness and market influence. Chang and Shaw [39] in their study differentiate the firms which have not adopted IT tools for SC collaboration from the firms which have already initiated IT-enable SC collaboration. These authors argue that, while non-adopters require a greater level of corporate technology readiness before adoption, initiators of SC collaboration need to reduce the lock-in costs (i.e., cost of joining the collaboration) and improve the organizational complementarity for achieving an effective adoption process. Moreover, companies require a ready SC environment -at industry level- for expanding their inter-organizational SC collaboration. In addition, processes with the highest IT capability, product complexity, and trustworthy relationships should be chosen first when companies start to implement SC collaboration, since "a ready SC and supportive market conditions are key factors for firms to implement higher penetration of SC collaboration" [39]. Also, for firms operating in the fully utilized adoption stage, partners with the large trading volume and in the stable and concentrated markets should be chosen first for penetration strategies.

\subsection{E-Marketplace Adoption Readiness}

Another aspect of readiness of organizations to adopt B2B EM enable SCs is their level of readiness to integrate EMs into their processes. In an empirical study on the readiness of large organizations to adopt EMs, Pucihar [40] identifies three groups of factors that influence the degree of readiness of organizations to adopt EMs. These factors are found to be: Organizational factors, EM factors, and environmental factors. She also points out the fact that the concept of readiness concerns all parties involved in the EM namely buyer(s), seller(s) and intermediaries(s). Pucihar [40] in this study focused on organizational factors. Organizational factors affecting the adoption of EM are categorized into four groups: 1. knowledge and experiences about e-Marketplace, 2. the level of E-Commerce development, 3. availability of IT personnel and resources, 4 . ability to connect with business partners. The first factors was measured by 'awareness of successful cases of EM use', 'awareness and knowledge about possible benefits of EM use', 'awareness and knowledge about possible threats of EM use', and 'awareness and knowledge about selecting the relevant type of EM'. The second factors was measured by the level of 'top management support to new IT and ways of business', 'formulated e-commerce strategy', 'sufficient IT department support in the organization', and 'defined position of e-commerce executive in organization'. Availability of IT personnel and resources (the third factor) was measured by the availability of 'trained employees with knowledge', 'modern IT infrastructure', 'experiences with e-commerce', and 'ecatalogue of products and services'. Finally, the ability to connect with business partners (the forth factor) was measured by the 'readiness of business processes to connect with business partners', 'use of ERP system that enables connecting with 
business partners', and 'use of e-commerce standards'. More studies are required to explore environmental factors and EM factors affecting the readiness of organizations to adopt e-commerce solutions such as B2B EMs into their operations.

\subsection{Factors Affecting the Adoption Process of E-Marketplaces}

In this part of the study factors that enhance the adoption of B2B EMs in SC of organizations are presented. Neill and Purchase [41] in their empirical study on B2B EMs showed that B2B EMs have significant positive impact on the long-term relationships among firms. Based on the works of several studies seven factors were identified to be critical to the development and adoption of EMs [41-43]. These factors are: the required number/amount of customers/transactions in EMs that ensures the operational and financial aspects of the EM (critical mass), the cost of establishing the EM and income stream (liquidity), independence and neutrality of the EM (i.e., the absence of bias in EM towards one or a group of market player/s), security/credibility/trust, ease of use and reliability, value added services, and business relationships and networks. Moreover, $\mathrm{Li}$ and $\mathrm{Li}$ [44] in their study on critical success factors of B2B EMs, proposed three categories of success factors: Functional Factors, Strategic Factors, and Technical Factors. Functional factors include "facilitation of product customization", "support for bidding and/or negotiation", and "access to a similar interest user community". The core functions of B2B EMs as described by Kearney [45] are: commerce, content, and collaboration. Strategic factors depend on the strategic positioning of the market players. Depending on the targeted buyer and seller segments and the type of products on the EM, market players may decide to pursue different strategies such as "first-to-market, brand establishment, customer focus, targeted marketing, outsourcing, and development of a customer or user community" [44]. Technical factors refer to the performance objectives of the EM to satisfy all participants' needs. It is mainly concerned with the quality of services that EM provides such as "response time, throughput, compatibility and reliability" [44]. These set of factors (Strategic factors, Functional factors, and Technical factors) can increase the success of B2B EMs through 'value creation' and 'building liquidity'. It is important to note that Liquidity along with value creation is the most important measure of EM success [46].

\section{CONCLUSIONS}

This paper explored the application of B2B EMs for enhancing the quality of SC through integrating inter-organizational SCs. In this study the scope and dimensions of the quality in $\mathrm{SC}$ was defined. In the next step the way to enhance different dimensions of SC quality was explored and a SC quality enhancement model was proposed. The application of IT was found to be one of the methods of enhancing the quality of SC. Different types of EMs, and success factors of adopting B2B EMs were introduced. In regards to the types of EMs, the results of this study show that the vertical and horizontal B2B EMs are both widely employed for the purpose of SC integration. Moreover, integration of SCs through B2B EMs is a 'systematic sourcing' 
rather than a 'spot sourcing'. From 'ownership' perspectives, all types of B2B EMs can be used for SC integration. However only 'closed' B2B EMs are found to have application in $\mathrm{SC}$ integration, while there exists no evidence of the application of 'open' B2B EMs in SC integration. The results of this study reveal that for adopting $\mathrm{B} 2 \mathrm{~B}$ EMs in $\mathrm{SC}$, one of the most important issues facing the managers is the degree of readiness of the adopting organizations to undergo the change process. This readiness includes two aspects: the readiness of the organizations for SC collaboration, and the readiness of organizations to adopt the EM business model. Future studies for validating these success factors and the exploring the transition process from traditional SCs to B2B EM enabled SCs are required.

\section{REFERENCES}

1. C.J. Robinson and M.K. Malhotra, Defining the concept of supply chain quality management and its relevance to academic and industrial practice, Int. J. Production Economics. Volume 96, pp.315-337, (2005).

2. Chen and Paulraj, Understanding supply chain management: critical research and a theoretical framework, International Journal of Production Research. Volume 42, Number 1, pp.131-163, (2004).

3. Supply Chain Council, Supply-chain operations reference model overview of SCOR version 5.0. (2001). http://www.supplychain.org

4. C-H. Kuei, C.N. Madu, C. Lin, and W.S. Chow. Developing supply chain strategies based on the survey of supply chain quality and technology management, International Journal of Quality \& Reliability Management. Volume 19, Number 7, pp.889-901, (2002).

5. D.A. Garvin, Competing on the Eight Dimensions of Quality, Harvard Business Review. Volum 65, Number 6, pp.101-109, (1987).

6. L.L. Berry and A. Parasuraman, Marketing Services - Competing through Quality (The Free Press: New York, NY, 1991).

7. C.N. Madu and A.A. Madu, Dimensions of e-quality, International Journal of Quality \& Reliability Management. Volume 19, Number 3, pp.246-58, (2002).

8. C.N. Madu and A.A. Madu, E-quality in an integrated enterprise, The TQM Magazine. Volume 15, Number 3, pp.127-136, (2003).

9. D.A. Garvin, Competing on the eight dimensions of quality, Unconditional Quality, Harvard Business Review. pp.43-51, (1991).

10. M.M. Chiu and G. Lin, Collaborative supply chain planning using the artificial neural network approach, Journal of Manufacturing Technology Management. Volume 15, Number 8, pp.787-796, (2004).

11. J. Olhager and E. Selldin, Supply chain management survey of Swedish manufacturing firms, International Journal of Production Economics. Volume 89, pp.353-361, (2004).

12. S. Yossi, Building a Resilient Supply Chain, $H B R$ newsletter. Volume 1, Number 8, pp.1$4,(2005)$.

13. B.M. Beamon and M.W. Tonja, A Process Quality Model for the Analysis, Improvement, and Control of Supply Chain Systems, Logistics Information Management. Volume 11, Number 2, pp.105-113, (1998).

14. J. Van and D. Vorst, Performance Measurement in Agri-food Supply-Chain Networks, Quantifying the agri-food supply chain, eds. C.J.M. Ondersteijn, J.H.M. Wijnands, R.B.M. Huirne and O.V. Kooten (Springer: Netherlands, 2006), pp.13-24. 
15. J. Li and L. Li, On the Critical Success Factors for B2B E-marketplace, in Proc. of the 7th international conference on Electronic commerce. ISBN: 1-59593-112-0 (2005), pp.119122.

16. P. Ward, Cash-to-cash is what counts, Journal of Commerce. Volume 5, Number 7, p.54, (2004).

17. C. Kuei and C. Madu, Identifying critical success factors for supply chain quality management, Asia Pacific Management Review. Volume 6, Number 4, pp.409-423, (2001).

18. H. White and E. Daniel, The future of online retailing in the UK: learning from experience, Marketing Intelligence \& Planning. Volume 22, Number 1, pp.10-23, (2004).

19. T.W. Malone, J. Yates, and R.I. Benjamin, Electronic Markets and Electronic Hierarchies, Communications of the ACM. Volume 30, Number 6, pp.484-497, (1987).

20. E.K. Clemons and M.C. Row, Information technology and industrial cooperation: The Changing Economics of Coordination and Ownership, Journal of Management Information Systems. Volume 9, Number 2, pp.9-28. (1992).

21. J.Y. Bakos and E. Brynjolfsson, From Vendors to Partners: Information Technology and Incomplete Contracts in Buyer-Supplier Relationships, Journal of Organizational Computing, Volume 3, Number 3, pp.301-328, (1993).

22. E.K. Clemons, S.P. Reddi, and M.C. Row, The Impact of Information Technology on the Organization of Production: The Move to the Middle Hypothesis, Journal of Management Information Systems. Volume 10, Number 2, pp.9-35, (1993).

23. M. Christopher and H. Peck, Building the Resilient Supply Chain, International Journal of Logistics Management. Volume 15, Number 2, pp.1-13, (2004).

24. M. Singh and D. Waddell, E-Business Innovation and Change Management (IGI Global, 2003).

25. T. Eng, the Role of E-marketplaces in Supply Chain Management, Industrial Marketing Management. Volume 33, pp.97-105, (2004).

26. J.Y. Bakos, the Emerging Role of Electronic Marketplaces on the Internet, Communications of the ACM. Volume 41, Number 8, pp.35-42, (1998).

27. J. Coppel, E-Commerce: Impacts and Policy Challenges, OECD Economics Department, Working Paper (2000), pp.252.

28. Q. Dai and R. Kauffman, to Be or Not to B2B? An Evaluative Model for E-Procurement Channel Adoption, Working Paper, Carlson School of Management, University of Minnesota, Minneapolis (MN, 2000).

29. T.R. Madanmoban, V. Kumar, and U. Kumar, Success or Failure of E-Marketplaces, Proceedings of Technology and Innovation Management Division (Administrative Sciences Association of Canada, 2006).

30. M. Grieger, Electronic Marketplaces: A Literature Review and a Call for Supply Chain Management Research, European Journal of Operations Research. Volume 144, Number 2, pp.280-294, (2003).

31. M. Grieger, an Empirical Study of Business Processes Across Internet-Based Electronic Marketplaces A Supply Chain Management Perspective, Business Process Management Journal. Volume 10, Number 1, pp.80-100, (2004).

32. A. Kambil and E.V. Heck, Book Reviews: Market Models and Marketplaces in the Digital Economy (Harvard Business School Press: Boston, USA, 2002).

33. K.C. Laudon and C.G., Traver, E-commerce: Business, Technology, Society (AddisonWesley Reading: MA, 2002).

34. M.B. Murtaza, V. Gupta, and R.C. Carroll, E-marketplaces and the Future of Supply Chain Management: Opportunities and Challenges, Business Process Management Journal. Volume 10, Number 3, pp.325-335, (2004).

35. E. Turban, D. King, J. Lee, M. Warkentin, and H.M. Chung, Electronic Commerce (Prentice-Hall: Englewood Cliffs, NJ, 2002). 
36. T.W. Malone, J. Yates, and R.I. Benjamin Electronic Markets and Electronic Hierarchies, Communications of the ACM. Volume 30, Number 6, pp.494-497, (1987).

37. M. Krantz, The next e-volution, Times Canada. Volume 154, Number 2, p.45, (1999).

38. H. Chang and M. Schaw, Developing the Readiness Index of IT-enabled Supply Chain Collaboration. Center for IT and e-Business Management (University of Illinois and Urbana Champaign: 2004). http://citebm.business.uiuc.edu/RN\%20study/Rosettanet.htm

39. A. Pucihar, Country Specific Look into E-Marketplaces - Case of Slovenia, in Proceedings of RSEEM (2005).

40. M. Neill and S. Purchase, An Asian Perspective on Airline Industry E-Markets, Australasian Marketing Journal. Volume 12, Number 1, pp.37-50, (2004).

41. W.D. Raisch, the E-Marketplace: Strategies for Success in B2B E-Commerce (McGrawHill, New York, 2001).

42. Kandampully, B2B Relationships and Networks in the Internet Age, Management Decision. Volume 41, Number 5, pp.443-451, (2003).

43. J. Li and L. Li, On the Critical Success Factors for B2B E-marketplace, ICEC'05 (Xi'an, China, 2005), pp.15-17.

44. A.T. Kearney, Building the B2B Foundation - Positioning the Net Market Makers for Success (A.T. Kearney Inc: Chicago, IL. 2000).

45. P. Brunn, M. Jensen, and J. Skovgaard, E-marketplaces: Crafting a Winning Strategy, European Management Journal. Volume 20, Number 3, 286-298 (2002).

46. H.L. Lee, The Triple-A Supply Chain, Harvard Business Review. Volume 82, Number 10, pp.102-112, (2004).

47. S.G. Roshan and N. Viswanadham, Strategic Sourcing and Collaborative Planning in Intenet-Enabled Supply Chain Networks Producing Multigeneration Products, IEEE Transactions on Automation Science and Engineering. Volume 4, Number 2, pp.45-66, (2007). 